\title{
Gas production kinetics in predictions of voluntary intake of grass silage by cattle*
}

\author{
S.J. Krizsan ${ }^{1,2,3}$, M. Hetta ${ }^{2}$, Å.T. Randby ${ }^{1}$ and P. Huhtanen ${ }^{2}$ \\ ${ }^{I}$ Norwegian University of Life Sciences, Department of Animal and Aquacultural Sciences \\ P.O. Box 5003, NO-1432 As, Norway \\ ${ }^{2}$ Swedish University of Agricultural Sciences, \\ Department of Agricultural Research for Northern Sweden \\ S-901 83 Umeå, Sweden
}

(Received 18 October 2011; revised version 28 February 2012; accepted 18 June 2012)

\begin{abstract}
The objective of this study was to predict voluntary intake by cattle of grass silages of different fermentation quality from in vitro gas production data. Further, biological concepts of intake related gas data were examined by cluster analysis to silage chemical composition. Samples from 24 grass silages were characterized from their gas profiles. Observed silage dry matter intake was modelled by partial least squares regression analysis. Cumulative gas volumes and rates of gas production during early incubation, asymptotic gas volume as well as discrete lag time, and cumulative gas volumes at 48 and $72 \mathrm{~h}$ were the best descriptors of the variation in silage intake. The discrete lag time had a strong negative influence on intake and made up clusters with chemical variables indicating secondary fermentation. In vitro gas production data did not improve silage dry matter intake predictions compared with current models based on chemical analysis of silage fermentation quality.
\end{abstract}

KEY WORDS: cattle, fermentation quality, gas in vitro, grass silage, prediction, voluntary intake

\section{INTRODUCTION}

Digestibility is the main factor affecting forage intake. The production of fermentation end products during silage preservation has been shown to reduce the intrinsic intake potential of the harvested grass (Huhtanen et al., 2002). The reasons for a lower intake of extensively fermented silages, and even high lactate silages, compared with restrictively fermented silages are not entirely clear. The

\footnotetext{
* Supported by the Research Council of Norway

${ }^{3}$ Corresponding autor: e-mail: sophie.krizsan@slu.se
} 
most pronounced change in the nutrient composition of grass due to ensiling is the depletion of water soluble carbohydrates (WSC) as a result of fermentation to lactic acid (LA) and volatile fatty acids (VFA) (McDonald et al., 1991). Silage fermentation products provide less energy than WSC to the rumen microorganisms; synthesis of microbial protein in the rumen can be reduced (Jaakkola et al., 2006a) and affect the ratio of amino acids to energy available at tissue level. An imbalance between amino acids and energy could explain a reduction in intake of extensively fermented silages, in line with positive intake responses to supplementary protein in cows fed grass silage-based diets (Oldham, 1984; Huhtanen et al., 2008a).

Intake of forages has been successfully modelled by gas production derived data from the early stages of the in vitro incubations (Blümmel and Ørskov, 1993; Blümmel et al., 1997, 2005; Rodrigues et al., 2002) emphasising the importance of the soluble fraction of the feed on the voluntary intake. Because WSC are already fermented to LA and VFA in silage, gas produced during the initial in vitro fermentation would be smaller from extensively compared with restrictively fermented silages. Effects of application of fermentation stimulants as well as inhibitors in ensiling have been detected on the soluble feed fraction with the in vitro gas production method (Beuvink and Spoelstra, 1994; Hetta et al., 2003). Measurements of in vitro gas production could therefore potentially be used to predict changes in energy supply for rumen microbes at early stages of rumen fermentation and explain the variation in intake of grass silage of different fermentation quality.

Development of automated systems to determine gas production from pressure changes in the incubation bottles (Pell and Schofield, 1993; Cone et al., 1996) allowed collection of large number of data for analysis of digestion kinetics by different mono- and multiphasic mathematical models and estimates of first order digestion rates $\left(\mathrm{k}_{\mathrm{d}}\right)$ (Huhtanen et al., 2008b). Partial least squares regression (PLSR) was judged to be more suitable compared to multiple regression analysis for the purpose of this study because the number of variables is allowed to exceed the number of samples, and collinearity is actively utilized in the analysis (Martens and Martens, 2001). The objectives with this work were to evaluate whether gas production derived variables would be biologically valid and better descriptors of the variation in intake related to grass silage fermentation quality than the end products of fermentation themselves.

\section{MATERIAL AND METHODS}

Feed samples and in vivo experimental design

Feed samples subjected to the in vitro incubation were from 24 low dry matter $(\mathrm{DM})$ silages produced at Hellerud Research Station in Norway $\left(60^{\circ} \mathrm{N}\right.$, 
Table 1. Descriptive statistics of the silages, intake, chemical composition and in vitro digestibility of the 24 silage samples subjected to in vitro gas production incubations

\begin{tabular}{|c|c|c|c|c|}
\hline Parameter $^{1}$ & Mean & SD & Minimum & Maximum \\
\hline SDMI, kg $100 \mathrm{~kg}^{-1}$ of BW & 2.38 & 0.196 & 1.79 & 2.65 \\
\hline SDMI index & 104 & 1.5 & 101 & 107 \\
\hline \multicolumn{5}{|l|}{ In vitro digestibility, $\mathrm{g} \mathrm{kg}^{-1}$} \\
\hline organic matter & 879 & 9.6 & 862 & 895 \\
\hline NDFom & 805 & 8.0 & 792 & 823 \\
\hline \multicolumn{5}{|c|}{ Chemical composition, $\mathrm{g} \mathrm{kg}^{-1}$ of DM unless otherwise stated } \\
\hline dry matter, $\mathrm{g} \mathrm{kg}^{-1}$ & 213 & 17.6 & 166 & 237 \\
\hline organic matter & 916 & 6.4 & 902 & 930 \\
\hline NDF & 544 & 33.5 & 476 & 601 \\
\hline acid detergent fibre & 348 & 15.0 & 325 & 383 \\
\hline lignin (sa) & 40.1 & 8.27 & 28.2 & 63.9 \\
\hline crude protein ${ }^{2}$ & 174 & 8.7 & 158 & 193 \\
\hline WSC & 33 & 15.4 & 16 & 70 \\
\hline ethanol & 6.8 & 2.40 & 3.4 & 13.2 \\
\hline $\mathrm{pH}$ & 4.56 & 0.338 & 4.01 & 5.26 \\
\hline acetic acid & 29 & 14.6 & 12 & 65 \\
\hline propionic acid & 1.0 & 1.61 & 0.0 & 5.2 \\
\hline butyric acid & 6.0 & 8.31 & 0.0 & 25.1 \\
\hline lactic acid (LA) & 49 & 23.9 & 2 & 102 \\
\hline total $\mathrm{VFA}^{3}$ & 36 & 22.1 & 12 & 86 \\
\hline total $\operatorname{acids}^{4}(\mathrm{TA})$ & 85 & 20.1 & 48 & 142 \\
\hline LA/TA & 0.58 & 0.235 & 0.03 & 0.83 \\
\hline $\mathrm{NPN}, \mathrm{g} / \mathrm{kg}$ of total $\mathrm{N}$ & 605 & 70.5 & 461 & 719 \\
\hline TSP, $\mathrm{g} / \mathrm{kg}$ of total $\mathrm{N}$ & 37 & 17.5 & 4 & 75 \\
\hline ADIN, $g / \mathrm{kg}$ of total $\mathrm{N}$ & 19 & 4.9 & 12 & 29 \\
\hline $\mathrm{NH}_{3}{ }^{5}, \mathrm{~g} / \mathrm{kg}$ of total $\mathrm{N}$ & 142 & 41.5 & 62 & 255 \\
\hline 2-phenyl-ethylamine & 0.10 & 0.083 & 0.00 & 0.26 \\
\hline histamine & 0.35 & 0.396 & 0.00 & 1.43 \\
\hline tryptamine & 0.09 & 0.151 & 0.00 & 0.64 \\
\hline tyramine & 1.49 & 0.650 & 0.29 & 2.68 \\
\hline putrescine & 1.44 & 0.897 & 0.17 & 3.73 \\
\hline cadaverine & 1.4 & 1.34 & 0.1 & 5.4 \\
\hline total amines & 4.8 & 3.22 & 1.0 & 13.8 \\
\hline
\end{tabular}

SDMI - silage dry matter intake; NDFom - neutral detergent fibre expressed free of residual ash; NDF - neutral detergent fibre inclusive of residual ash; WSC - water soluble carbohydrates; VFA - volatile fatty acids; NPN - nonprotein N; TSP - true soluble protein; ADIN - acid detergent insoluble $\mathrm{N}$; sa - sulphuric acid; ${ }^{2}$ crude protein calculated from total $\mathrm{N}$ corrected for additivederived $\mathrm{N} ;{ }^{3}$ total VFA = acetic acid + propionic acid + butyric acid $;{ }^{4}$ total acids $=$ total VFA + lactic acid; ${ }^{5}$ corrected for additive-derived $\mathrm{N}$

$11^{\circ} \mathrm{E}$ ) on 3 to 5 June 2002 . The aim was to produce silages displaying a wide variation in fermentation quality from grass harvested at equal maturity. The silages were made from the same crop ( $>80 \%$ Phleum pratense) harvested within $60 \mathrm{~h}$. The crop was harvested by different harvesters, and ensiled in diverse silo types with different additives and application rates of the additives. 
The voluntary intake of the 24 silages was determined in a previous feeding trial with 30 growing Norwegian Red steers (Krizsan and Randby, 2007). Five different forages were fed in each of the five periods using a partially balanced change-over design. Each experimental period consisted of 2 weeks of feeding all animals the same standard silage, followed by 3 weeks of feeding experimental feed of which the last 2 weeks were used to determine silage DM intake (DMI). The 2-week periods with standard silage removed possible variation in intake due to carry-over effects and were used as covariate in the statistical analysis to correct for intake variation due to animal (Abrams et al., 1987). Average and ranges of silage DMI and chemical composition parameters of the 24 silages are given in Table 1. Silage samples were collected days 9, 12, 14, 16, 19 and 21 during periods of experimental feeding. Composite samples of the 24 silages were used in the gas in vitro incubations. The samples were freezedried and ground to pass a $1 \mathrm{~mm}$ screen with Retsch Impeller-Type Mill SM1 (Retsch GmbH \& Co. KG, Haan, Germany). Further information of experimental design, preparation, and detailed chemical composition of the silages were presented in previous papers (Krizsan and Randby, 2007; Krizsan et al., 2007).

\section{Chemical analyses and in vitro gas incubations}

Prior to the in vitro incubations the concentrations of ash and the neutral detergent fibre free of residual ash (NDFom) were determined in the freeze-dried silage samples. Neutral detergent fibre was analysed according to the oven method (Chai and Udén, 1998) without addition of sodium sulphite or amylase. Samples were analysed for DM by oven drying at $105^{\circ} \mathrm{C}$ for $16 \mathrm{~h}$. Ash concentration in the dried samples were determined by ignition at $550^{\circ} \mathrm{C}$ for $4 \mathrm{~h}$. In vitro digestibility of NDFom and organic matter (OM) was determined for all silages by analysing the NDFom concentrations in the residues after the $72 \mathrm{~h}$ gas in vitro incubations. Apparently digestible $\mathrm{OM}$ in silage DM (data not presented) was estimated by subtracting 100 from the gas in vitro digestible $\mathrm{OM}$ (in $\mathrm{g} \mathrm{kg}^{-1} \mathrm{DM}$ ), representing the metabolic and endogenous OM in faeces (Huhtanen et al., 2006b). Relative silage DMI index for the silages was determined according to Huhtanen et al. (2007).

Rumen fluid was obtained from two Swedish Red and White heifers $2 \mathrm{~h}$ after the morning feeding. The heifers were fed a balanced forage based diet of hay and silage twice daily. Body weight (BW) of the heifers were on average $350 \mathrm{~kg}$ at the time for the collection of rumen fluid. The rumen fluid was collected with a flexible probe per os and kept in preheated thermos flasks. It was filtered through two layers of cheesecloth and mixed with a buffer-mineral solution (Menke and Steingass, 1988). The volume ratio of rumen fluid to buffer was 1:2. All manipulations with the rumen fluid were done under continuous flushing with $\mathrm{CO}_{2}$. Approximately $400 \mathrm{mg}$ of $\mathrm{OM}$ from each silage sample were incubated in 
$60 \mathrm{ml}$ of buffered rumen fluid for $72 \mathrm{~h}$ in $250 \mathrm{ml}$ serum bottles (Schott, Mainz, Germany). Incubations were conducted at $39^{\circ} \mathrm{C}$ and the bottles were continually gently agitated. Recordings of each sample were repeated in four consecutive runs. Duplicate samples of standard hay were included in every run. Registrations of gas production were made with an automated system with release of gases when the pressure sensors register a pre-set gas pressure (Cone et al., 1996). Recorded gas volumes were corrected to normal atmospheric pressure $(1013.5 \mathrm{hPa})$.

\section{Mathematical models, curve fitting and effective first order digestion rate}

For each sample, a mean gas curve was calculated from four replicates. The derivatives (gas production rates) were calculated using a non-parametric smoothing spline procedure in Tablecurve 2D (Version 5.0® SPSS Inc. Chicago, IL, USA). Three different mathematical models were fitted to the gas production profiles: an exponential equation including a discrete lag time (EXP $\mathrm{DLag}_{\text {; }}$; equation 1) as described by Dhanoa (1988), an empirical multiphase model as described by Groot et al. (1996) (GROOT, equation 2) and the Gompertz equation derived by Schofield et al. (1994) (GOMP 3 ; equation 3):

$$
\begin{gathered}
\mathrm{V}_{\mathrm{t}}=\mathrm{V}\left\{1-\mathrm{e}^{-[\mathrm{k} \times(\mathrm{t}-\mathrm{L})]}\right\} \\
\mathrm{V}_{\mathrm{t}}=\mathrm{V}_{1} /\left[1+\left(\mathrm{B}_{1}^{\left.\mathrm{C}_{1} / \mathrm{t}^{\mathrm{C} 1}\right)}\right)+\mathrm{V}_{2} /\left[1+\left(\mathrm{B}_{2}^{\left.\mathrm{C}_{2} / \mathrm{t}^{\mathrm{C}}\right)}\right)\right]+\mathrm{V}_{2} /\left[1+\left(\mathrm{B}_{3}{ }^{\mathrm{C}_{3} / \mathrm{t}^{\mathrm{C}} 3}\right)\right]\right. \\
\mathrm{V}_{\mathrm{t}}=\mathrm{V}_{1} \times \exp \left\{-\exp \left[1-\mathrm{k}_{1} \times\left(\mathrm{t}-\mathrm{L}_{1}\right)\right]\right\}+\mathrm{V}_{2} \times \exp \left\{-\exp \left[1-\mathrm{k}_{2} \times\left(\mathrm{t}-\mathrm{L}_{2}\right)\right]\right\}+ \\
\mathrm{V}_{3} \times \exp \left\{-\exp \left[1-\mathrm{k}_{3} \times\left(\mathrm{t}-\mathrm{L}_{3}\right)\right]\right\}
\end{gathered}
$$

where: $\mathrm{V}_{\mathrm{t}}$ - volume of gas at time $\mathrm{t}\left(\mathrm{ml}\right.$ gas $\left.\mathrm{g}^{-1} \mathrm{OM}\right), \mathrm{V}$ - asymptotic gas volume $\left(\mathrm{ml}\right.$ gas g $\left.{ }^{-1} \mathrm{OM}\right), \mathrm{k}$ - rate parameter $\left(\mathrm{h}^{-1}\right), \mathrm{L}$ - lag parameter $(\mathrm{h}), \mathrm{B}$ - the time at which half of the asymptotic value of gas was produced (h), $\mathrm{C}$ - the dimensionless shape parameter.

The subscript of the parameters V, B, C, and L denotes the pool described (1, 2, and 3 for the fast, slow and microbial pools, respectively; Cone et al., 1997). The exponential equation described a one-pool model, while both Groot and Gompertz equations accommodated three pools. The models were fitted to the data by the NLIN procedure in SAS. Average in vitro fermentation rates of the fast and slow pools in the three-pool Groot model were calculated as $\mathrm{V} /(2 \times \mathrm{B})$. The point of inflection was determined for the second subcurve, and maximum fractional rate of substrate digestion and the time at which maximum fractional rate of substrate digestion occurs were calculated according to Groot et al. (1996).

The parameter values estimated from the gas production profiles were used in a dynamic mechanistic rumen model to predict ruminal digestibility of truly digestible OM according to the predictions of ruminal digestibility of potentially 
digestible NDF as described by Huhtanen et al. (2008c). The two-compartment rumen passage model (Allen and Mertens, 1988) used $50 \mathrm{~h}$ of rumen residence time distributed between the compartments in a ratio of 40:60 between the nonescapable and escapable pools. In the exponential model including a discrete lag, the digestion began at the lag time, but the release of feed particles from the non-escapable pool to the escapable pool commenced at time zero. The rumen models were constructed using Powersim software (Powersim Software AS, Bergen, Norway). Effective first order $\mathrm{k}_{\mathrm{d}}$ was calculated according to the equation described by Huhtanen et al. (2006a).

\section{Statistical analyses}

To evaluate the relationships between silage fermentation characteristics and gas production and between gas production and DMI simple correlations were calculated for each time point (h) during the first $24 \mathrm{~h}$ of incubation.

Least squares means of silage DMI (estimated with the MIXED procedure in SAS including effects of treatment and covariate adjustment; Krizsan and Randby, 2007) were used as response variable in a PLSR in The Unscrambler $\mathrm{X}$ (Version 10.0.1®; Camo, Oslo, Norway). The relationship between silage intake and variables of gas production kinetics was examined by 2-block bilinear modelling:

$$
\mathrm{X}=\mathrm{x}+\mathrm{T}_{\mathrm{A}} \mathrm{P}_{\mathrm{A}}{ }^{\prime}+\mathrm{E}_{\mathrm{A}} \text { and } \mathrm{Y}=\mathrm{y}+\mathrm{T}_{\mathrm{A}} \mathrm{Q}_{\mathrm{A}}{ }^{\prime}+\mathrm{F}_{\mathrm{A}}
$$

where: a set of $\mathrm{X}$-variables collected in the $\mathrm{X}$ matrix are decomposed into a $\mathrm{y}$-relevant score matrix for A factors or A t-vectors, $T_{A}$, which were used to model both $\mathrm{X}$ and $\mathrm{y}$ in terms of the loading matrices $\mathrm{P}_{\mathrm{A}}$ ' and $\mathrm{Q}_{\mathrm{A}}$, and their residuals $\mathrm{E}_{\mathrm{A}}$ and $\mathrm{F}_{\mathrm{A}}$.

Variables in the PLSR analysis were standardized to mean of zero and an initial standard deviation of one (each variable was divided by its initial standard deviation) so that only the relative differences among the variance of the variables influenced the model. Variables describing silage digestibility and composition were made passive, i.e. they were scaled by a factor of $10^{-5}$ in the PLSR. Thereby, these variables did not influence the analysis, but were subjected to the uncertainty test and could be viewed in relation to the variables describing gas production kinetics and intake (Martens and Martens, 2001). The optimal number of factors in the model was defined at minimum cross validated root mean square error (RMSECV) in y-variable (silage DMI in $\mathrm{kg} / 100 \mathrm{~kg} \mathrm{BW}$ ). Variable selection among gas production kinetics was performed using jack-knifing as resampling method to estimate uncertainties of the loadings (Martens and Martens, 2000). Cluster analysis was performed with principal component analysis to provide groups of related variables among significant gas production kinetics and chemical components of the silages. Components were joined in clusters based on 
the Euclidean distance in the correlation-loading matrix of the two first principal components.

\section{RESULTS}

In vitro gas production, parameter estimates and model performance

The observed variation in cumulative gas production and gas production rate across all in vitro incubations is illustrated by four selected silage samples in Figure 1. The two silages with the highest asymptotic gas volumes had the highest DMI in the study by Krizsan and Randby (2007). These silages were treated with formic acid-based additives and were restrictively fermented. The two other silages, which were secondarily fermented, had the smallest observed intake (Krizsan and Randby, 2007). Generally, all silages displayed an immediate gas production, though the amount and rate of gas produced in the initial phase differed. Variation could also be seen in the asymptotic value of gas produced, but most samples approached this maximum value around the same time of the in vitro incubation (after $24 \mathrm{~h}$ ). The time for minimum rate of gas production for the silages varied between 1 and $3 \mathrm{~h}$. There was a subsequent increase in rate of gas production for all silages reaching the maximum point at $7-8 \mathrm{~h}$, and thereafter the rate steadily declined during the incubation time.
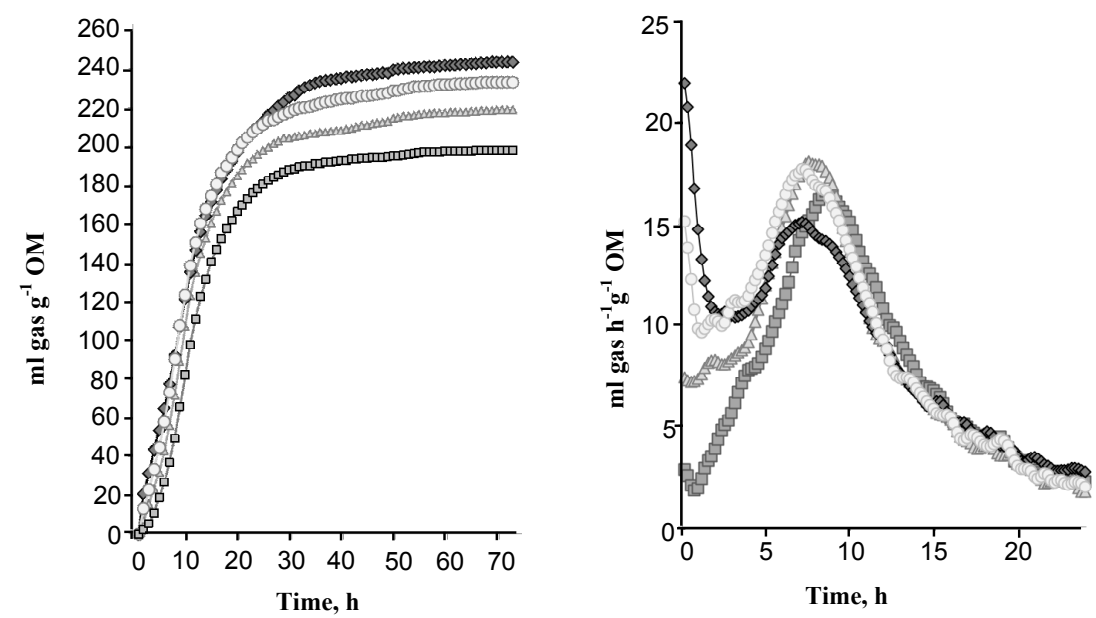

Figure 1. Differences in cumulative in vitro gas production during $72 \mathrm{~h}$ (left) and the first derivative of the cumulative gas production (right) during $24 \mathrm{~h}$ represented by four selected samples of the 24 grass silages. The $\diamond$ and $O$ silage samples had the highest intake and were restrictively fermented; $\Delta$ and $\square$ samples were from secondarily fermented silages and had the smallest observed intake (Krizsan and Randby, 2007) 
The descriptive statistics of the cumulative gas production profiles for the 24 silages described by the mathematical models (equations 1, 2, and 3) are presented in Table 2. The fit of all three models to the data was good with root

Table 2. Descriptive statistics of gas production parameters and effective first order digestion rates estimated from the gas production of the 24 silages by, the one-pool exponential equation with discrete lag $\left(\mathrm{EXP}_{\text {DLag }}\right)$, the three-pool Groot model $\left(\mathrm{GROOT}_{3}\right)$, and the three-pool Gompertz model $\left(\mathrm{GOMP}_{3}\right)$

\begin{tabular}{|c|c|c|c|c|}
\hline Parameter $^{1}$ & Mean & SD & Minimum & Maximum \\
\hline \multicolumn{5}{|l|}{$E X P_{D L \sigma \alpha}$} \\
\hline VL, ml g ${ }^{-1} \mathrm{OM}$ & 224 & 14.6 & 197 & 257 \\
\hline $\mathrm{k}, 1 \mathrm{~h}^{-1}$ & 0.117 & 0.0112 & 0.091 & 0.139 \\
\hline $\mathrm{L}, \mathrm{h}$ & 2.6 & 0.68 & 1.1 & 4.1 \\
\hline $\mathrm{k}_{\mathrm{d}}, 1 \mathrm{~h}^{-1}$ & 0.109 & 0.0080 & 0.093 & 0.121 \\
\hline \multicolumn{5}{|l|}{$\mathrm{GROOT}_{3}$} \\
\hline $\mathrm{V}_{1}, \mathrm{ml} \mathrm{g}^{-1} \mathrm{OM}$ & 105 & 24.6 & 60 & 172 \\
\hline $\mathrm{B}_{1}, \mathrm{~h}$ & 8.4 & 1.62 & 6.0 & 11.3 \\
\hline $\mathrm{C}_{1}$ & 1.31 & 0.470 & 0.86 & 3.01 \\
\hline $\mathrm{V}_{2}, \mathrm{ml} \mathrm{g}^{-1} \mathrm{OM}$ & 110 & 10.3 & 86 & 126 \\
\hline $\mathrm{B}_{2}, \mathrm{~h}$ & 11.6 & 14.50 & 7.9 & 79.6 \\
\hline $\mathrm{C}_{2}^{2}$ & 3.95 & 0.851 & 0.60 & 4.86 \\
\hline $\mathrm{V}_{3}^{2}, \mathrm{ml} \mathrm{g}^{-1} \mathrm{OM}$ & 20 & 11.6 & 7 & 60 \\
\hline $\mathrm{B}_{3}, \mathrm{~h}$ & 17.6 & 4.17 & 1.5 & 22.3 \\
\hline $\mathrm{C}_{3}^{3}$ & 6.78 & 1.549 & 4.55 & 9.13 \\
\hline $\mathrm{V}_{1}^{3} /\left(2 \times \mathrm{B}_{1}\right), \mathrm{ml} \mathrm{h}^{-1} \mathrm{~g}^{-1} \mathrm{OM}$ & 6.2 & 1.11 & 3.8 & 9.2 \\
\hline $\mathrm{V}_{2} /\left(2 \times \mathrm{B}_{2}\right), \mathrm{ml} \mathrm{h}^{-1} \mathrm{~g}^{-1} \mathrm{OM}$ & 6.5 & 0.75 & 0.5 & 7.7 \\
\hline $\mathrm{R}_{\mathrm{N}}, \mathrm{h}^{-1}$ & 0.276 & 0.0486 & 0.118 & 0.364 \\
\hline $\mathrm{t}_{\mathrm{RM}}^{\mathrm{M}}, \mathrm{h}$ & 11.3 & 0.73 & 10.5 & 13.4 \\
\hline $\mathrm{i}_{2}, \mathrm{~h}$ & 7.6 & 0.42 & 7.0 & 8.7 \\
\hline $\mathrm{k}_{\mathrm{d}}, \mathrm{h}^{-1}$ & 0.088 & 0.0186 & 0.043 & 0.131 \\
\hline \multicolumn{5}{|l|}{$\mathrm{GOMP}_{3}$} \\
\hline $\mathrm{V}_{1}, \stackrel{3}{\mathrm{ml} \mathrm{g}} \mathrm{g}^{-1} \mathrm{OM}$ & 33 & 28.4 & 10 & 127 \\
\hline $\mathrm{K}_{1}, \mathrm{~h}^{-1}$ & 0.310 & 0.1140 & 0.116 & 0.596 \\
\hline $\mathrm{L}_{1}, \mathrm{~h}$ & 5.3 & 1.90 & 0.1 & 6.7 \\
\hline $\mathrm{V}_{2}, \mathrm{ml} \mathrm{g}^{-1} \mathrm{OM}$ & 162 & 30.9 & 98 & 197 \\
\hline $\mathrm{K}_{2}, \mathrm{~h}^{-1}$ & 0.075 & 0.0139 & 0.046 & 0.107 \\
\hline $\mathrm{L}_{2}^{2}, \mathrm{~h}$ & 1.7 & 0.78 & 0.5 & 3.5 \\
\hline $\mathrm{V}_{3}, \mathrm{ml} \mathrm{g}^{-1} \mathrm{OM}$ & 32 & 17.3 & 6 & 83 \\
\hline $\mathrm{K}_{3}^{3}, \mathrm{~h}^{-1}$ & 0.041 & 0.0408 & 0.019 & 0.199 \\
\hline $\mathrm{L}_{3} \mathrm{~h}$ & 11.5 & 12.24 & 1.8 & 46.7 \\
\hline $\mathrm{k}^{3}, \mathrm{~h}^{-1}$ & 0.109 & 0.0116 & 0.092 & 0.135 \\
\hline
\end{tabular}

${ }^{1} \mathrm{~V}$ - asymptotic gas volume; $\mathrm{k}$ - time dependent rate; L - lag parameter; $\mathrm{B}$ - the time at which half of the asymptotic gas volume was produced; $\mathrm{C}$ - the dimensionless shape parameter; $\mathrm{R}_{\mathrm{M}}$ - maximum fractional rate of substrate digestion; $t_{\mathrm{RM}}$ - the time for maximum fractional rate of substrate digestion; $i_{2}$ - the point of inflection for the second subcurve; $k_{d}$ - effective first order digestion rate. The subscript in the Groot and Gompertz model denotes the pool number with 1 and 2 for the rapidly and slowly degradable substrate pools, respectively, and 3 for the gas pool generated from microbial turnover (Cone et al., 1997) 
mean squared error values averaging $1.8,0.2$, and $0.3 \%$ of the asymptotic gas volume across all silages for the $\mathrm{EXP}_{\mathrm{DLag}}, \mathrm{GROOT}_{3}$, and $\mathrm{GOMP}_{3}$ models, respectively. The observed asymptotic gas volume across all silages averaged $226 \pm 15.0 \mathrm{ml} \mathrm{g}^{-1} \mathrm{OM}$ and ranged between 198 and $259 \mathrm{ml} \mathrm{g}^{-1} \mathrm{OM}$. The observed data agreed well with model-predicted asymptotic gas volumes and ranges for the $\operatorname{EXP}_{\text {DLag }}\left(\right.$ mean $=224 \mathrm{ml} \mathrm{g}^{-1} \mathrm{OM}$; range: $\left.197-257 \mathrm{ml} \mathrm{g}^{-1} \mathrm{OM}\right)$ and $\mathrm{GOMP}_{3}$ (mean $=227 \mathrm{ml} \mathrm{g}^{-1} \mathrm{OM}$; range: $197-260 \mathrm{ml} \mathrm{g}^{-1} \mathrm{OM}$ ) models, while GROOT ${ }_{3}$ predicted greater values (mean $=236 \mathrm{ml} \mathrm{g}^{-1} \mathrm{OM}$; range: $198-272 \mathrm{ml} \mathrm{g}^{-1} \mathrm{OM}$ ). The ranges of predicted effective first order $k_{d}$ calculated using the time-dependent rate parameter estimate of the $\mathrm{GROOT}_{3}$ was also wider compared with estimates derived from the $\mathrm{EXP}_{\text {DLag }}$ and $\mathrm{GOMP}_{3}$ models (Table 2).

Gas production kinetics in relation to intake and chemical composition of the silages

The correlation coefficient between cumulative gas production and DMI reached maximum (0.67) with $5 \mathrm{~h}$ incubation (Figure 2). Thereafter the changes in correlation were rather small, probably because the differences in gas production at $5 \mathrm{~h}$ reflected well the differences during later incubation time points. The slope between gas production at $5 \mathrm{~h}$ and at each hour between 12 and $24 \mathrm{~h}$ ranged from 1.00 to 1.05 indicating that the differences produced at early stages of fermentation were maintained during the later stages of fermentation.

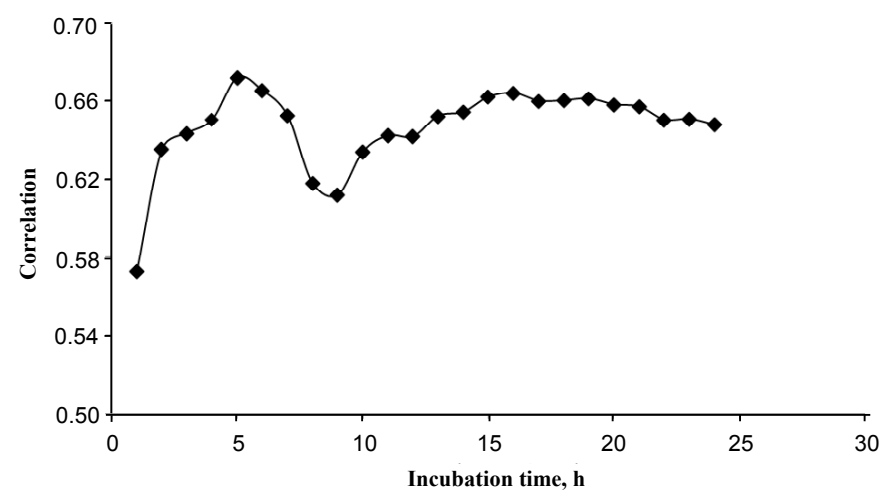

Figure 2. Correlation between silage dry matter intake and the cumulative gas production at increasing intervals during the first $30 \mathrm{~h}$ of incubation (data representing all 24 silages)

Concentration of VFA was strongly and negatively correlated with gas production with nadir being reached almost the same time $(6 \mathrm{~h})$ as the highest correlation between gas production and DMI. On the other hand, the correlations between total acids (= LA + VFA) or LA and gas production were much weaker 
than between VFA and gas production. A simple regression of cumulative gas production at $5 \mathrm{~h}$ on intake gave a root mean square error of calibration (RMSEC) of $0.148 \mathrm{~kg}$ DM $100 \mathrm{~kg}^{-1} \mathrm{BW}$.

The RMSECV of silage intake reached a minimum of $0.165 \mathrm{~kg}$ DM $100 \mathrm{~kg}^{-1} \mathrm{BW}$ after the first factor in the model with all 65 variables. The score plot (not presented) for the first two factors in the full model displayed an even distribution of samples along the first factor axis and no outlying objects were distinguished. The 35 gas profile variables that were selected as significant at $\mathrm{P} \leq 0.05$ from the uncertainty test estimated with jack-knifing were used in a second PLSR (Figure 3). Chemical components also selected at a 0.05 significance level are visualized in Figure 3, but without contributing to the explained variance of the response variable. The reduced bilinear model reached a minimum in RMSECV of $0.160 \mathrm{~kg}$ DM $100 \mathrm{~kg}^{-1} \mathrm{BW}$ after one factor.

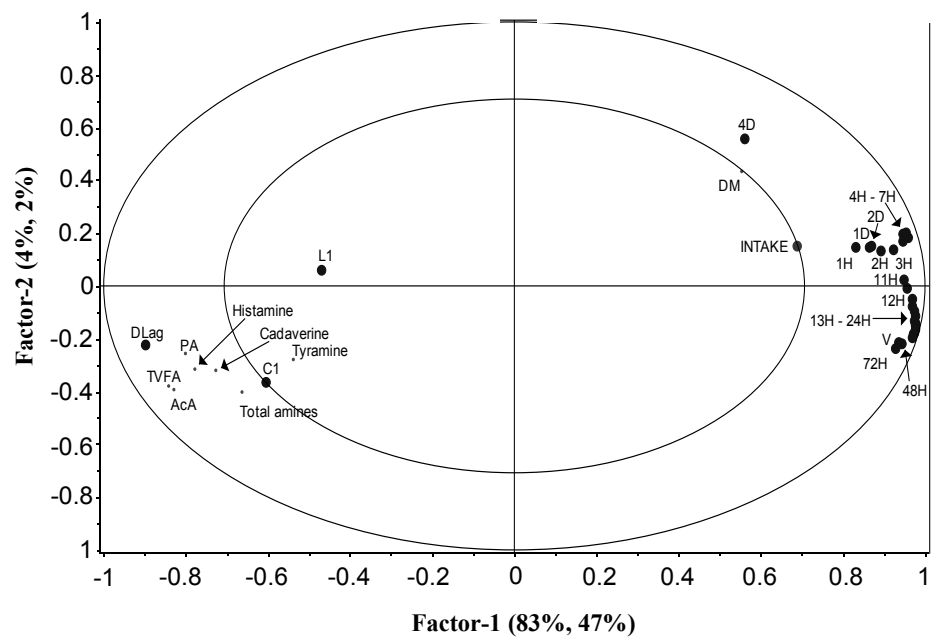

Figure 3. Correlation loading plot of Factor-2 vs Factor-1 after recalculation with significant $(\mathrm{P}<0.05)$ variables determined by jack-knifing. Abbreviations used in the plot are as follow: $1 \mathrm{H}, 2 \mathrm{H}, \ldots ., 72 \mathrm{H}$ are average cumulative gas produced every hour from the 72-h incubations; $1 \mathrm{D}, 2 \mathrm{D}$, and 4D are the first derivative of the cumulative gas produced at the first, second and fourth hour; DLag and V are the discrete lag and asymptotic gas volume from the exponential model; $\mathrm{C} 1$ the dimensionless shape parameter from the rapidly fermentable pool of the 3-pool Groot model; L1 the lag time from the rapidly fermentable pool of the 3-pool Gompertz model; AcA - acetic acid, PA - propionic acid and TVFA - total volatile fatty acids. Chemical variables are visualized, but without contributing to explained variance of silage dry matter intake $\left(\mathrm{kg} / 100 \mathrm{~kg}^{-1}\right.$ body weight; INTAKE). Explained variance in $\mathrm{X}$ and $\mathrm{Y}$ are given for respective factor in parenthesis on the axis. Factor axes are scaled according to the loading coordinates in the bilinear model 
The RMSEC in the 1-factor model was $0.139 \mathrm{~kg}^{\mathrm{DM}} 100 \mathrm{~kg}^{-1} \mathrm{BW}$. Calibrated and validated explained variance in silage DMI with the 1-factor model were 47 and $37 \%$, respectively. The relationship between predicted and observed DMI is presented in Figure 4.

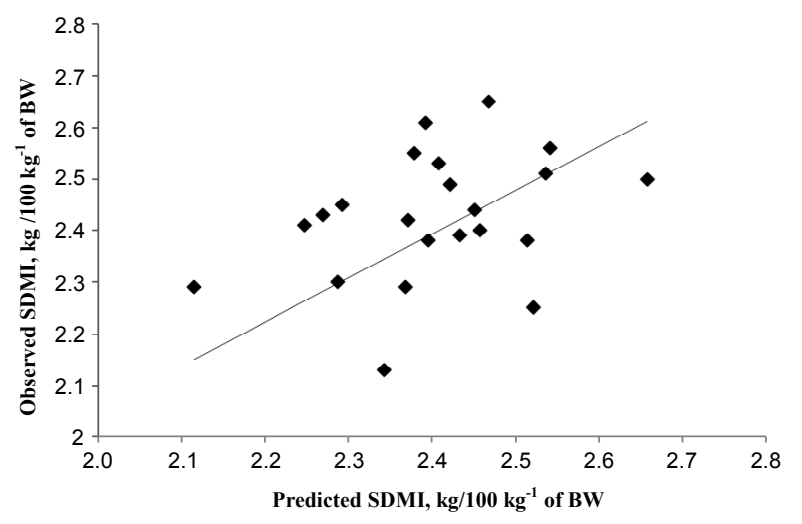

Figure 4. The relationship between observed and predicted (cross validated) silage dry matter intake (SDMI; kg $100 \mathrm{~kg}^{-1}$ of body weight (BW)) utilizing multivariate regression analysis, where observed $\mathrm{SDMI}=0.875 \times$ predicted $\mathrm{SDMI}+0.359$ and $\mathrm{R}^{2}=0.31$

The following variables made up one cluster that joined at a distance level of 0.034: cumulative gas production every hour up to $24 \mathrm{~h}$, except at 8,9 and $10 \mathrm{~h}$, and at 48 and $72 \mathrm{~h}$, the first derivative of the cumulative gas production at 1 and $2 \mathrm{~h}$, and the asymptotic gas volume of the $\mathrm{EXP}_{\text {DLag }}$ model. The first derivative of the cumulative gas production at $4 \mathrm{~h}$ and DM concentration joined earlier in another cluster at a distance level of 0.015 . Further, these two clusters joined at, or were separated by, a distance level of 0.11 . Two more clusters joined chemical component and gas production kinetic variables; tyramine and the shape parameter $\mathrm{C}$ for the first pool in GROOT 3 joined with lag time of first pool in $\mathrm{GOMP}_{3}$ at a distance level of 0.041 , and acetic acid and total volatile fatty acids joined with the discrete lag term of the EXP ${ }_{\text {DLag }}$ model at a distance level of 0.012. The last of these clusters joined with propionic acid, histamine, cadaverine, and total amines at a distance level of 0.048 , which further joined with tyramine, the shape parameter $\mathrm{C}$ for the first pool in GROOT 3 and lag time of first pool in $\mathrm{GOMP}_{3}$ at a distance level of 0.12 . The first 28 -variable cluster at 0.11 and the last 10 -variable cluster at 0.12 were finally separated by a distance level of 0.50 . 


\section{DISCUSSION}

\section{Mathematical models and biological interpretation of gas profile parameters}

Silage intake has not frequently been modelled from in vitro gas production data across a wide variation of experiments including feed quality factors that are the most influential on intake as well as on in vitro gas production recordings. Variable concentrations of forage chemical components (e.g., fermentation acids and crude protein concentration) within and between forage types complicate the interpretation across the relationships presented in the literature (Cone and Van Gelder, 1999; Hetta et al., 2007). In addition to cumulative gas volume measurements, dynamic model parameters and first order digestion rates were estimated from three different mathematical models in this study. Because automated gas production system provides a large amount of direct gas volume measurements it allows to estimate kinetic parameters with various mathematical models, and a large amount of data can be produced from a single sample. In addition, the mathematical models have evolved representing different general biological concepts (France et al., 2000).

Blümmel and Bullerdieck (1997) coupled the fast degradation rates of highintake hays to higher microbial yield and a lower VFA production per unit substrate degraded in vitro, but in the present study no first order rate constants were ranked among the 35 most important variables to intake of silage. The variables positively correlated to intake in the best model (the 35-variable model) in this study were located close to the outer ellipse in Figure 3, which represents $100 \%$ explained variance of y by the model. Silage DM concentration was the only chemical variable that joined in clusters with gas profile derived data that was positively related to intake. However, the distance of this cluster was larger than of that joining the discrete lag of the $\mathrm{EXP}_{\text {DLag }}$ model with the chemical components negatively related to silage intake. Also the location of DM concentration in Figure 3 indicated that the interpretation of the cluster between DM concentration and gas data was less relevant. The discrete lag of $\mathrm{EXP}_{\mathrm{DLag}}$, the shape parameter $\mathrm{C}$ and lag time from the rapidly fermentable pools derived from the $\mathrm{GROOT}_{3}$ and $\mathrm{GOMP}_{3}$ models were located almost directly opposed to intake (Figure 3).

It seems difficult to argue for separate clusters between gas production parameters and chemical components within the variables negatively correlated to intake, since most of them were located outside the inner ellipse and in the same quadrant in Figure 3. However, the discrete lag of the $\mathrm{EXP}_{\mathrm{DLag}}$ model was much closer to the outer ellipse in Figure 3 than the other gas in vitro derived variables, which indicates a stronger negative influence on silage intake of this variable. The discrete lag of the $\mathrm{EXP}_{\text {DLag }}$ primarily made up clusters with acetic acid and 
total VFA. Further, the close proximity to propionic acid, histamine, cadaverine and total amines suggested that the silage fermentation of WSC, and amino acids and peptides, to products typical of secondary fermented silages clearly depressed intake and depleted an initial gas production. The influence of silage fermentation end products on voluntary intake by cattle have been thoroughly evaluated in many studies, e.g., see Steen et al. (1998) and Huhtanen et al. (2002), and are in agreement with this interpretation. Lag is traditionally assumed to represent processes such as hydration of feeds, the time for microbial colonization and occurrence of analytically detectable digestion (Mertens, 1993). The variation in gas profiles of the samples in this study was rather seen as differences in curve inflection than a clear discrete lag (Figures 1 and 2). The discrete lag might be regarded as more apparent than true. Discrete lag is a mathematical parameter and describes the time taken to reach best fit of the first order rate in the exponential model. For the whole feed an increased lag may result from reduced gas from the neutral detergent soluble fraction, because it is less likely that silage fermentation would influence fibre characteristics. It is possible that the differences would be seen better from incubation of whole feed and NDF separately utilizing the curve subtraction techniques to evaluate the neutral detergent soluble fraction as described by Schofield and Pell (1995).

The differences in gas production during early stages of incubation were strongly related to silage VFA concentration suggesting that the relationship between gas production and DMI are associated with fermentation of WSC to VFA. The negative effect of discrete lag time on DMI may not be causal, because lag time was strongly and positively correlated with VFA concentration $\left(\mathrm{R}^{2}=\right.$ 0.81 ). Volatile fatty acids are also end products of rumen fermentation, and the gas production has already taken place during silage fermentation. In addition, silage VFAs are lost in drying of the samples (Huida et al., 1986), and consequently gas production related to the release of carbon dioxide from the buffer by VFA is eliminated. Smaller correlations between LA or total acids and gas production can be attributed negative relationship between LA and total acids and to probably variable pH-related losses of LA in drying the samples (Huida et al., 1986).

\section{Intake prediction}

Animal production performance depends primarily on the voluntary feed intake. Feed intake is regulated by several factors with the diet as well as the animal and its environment (Mertens, 1994). Huhtanen et al. (2007) stated that digestible $\mathrm{OM}$ in DM (D-value), total acid concentration and forage type were the primary factors in predictions of silage intake potential. Alternatively to silage D-value, measurements of extents and rates of substrate degradation have 
been used to predict the voluntary DMI of forages (Ørskov et al., 1988). The in vitro gas production technique is another method for dynamic description of feed fermentation, which was also suggested valid to predict forage intake accurately (Blümmel and Ørskov, 1993). Krizsan and Randby (2007) observed differences in daily intake of grass silage by growing steers of up to $0.86 \mathrm{~kg}$ of DM $100 \mathrm{~kg}^{-1} \mathrm{BW}$ due to variations in fermentation quality of the silages. The predictions of silage DMI from analysed silage fermentation quality parameters, where two different statistical approaches were used, were accurate with a relative RMSECV (cross validated residual error as proportion of the mean intake) of 4.1 or $5.6 \%$ (Krizsan and Randby, 2007), and 3.4\% (Krizsan et al., 2007). Despite the possibility of using the large number of data points generated in an automated gas production system, for both static model parameter estimates and detailed kinetic description of recorded gas volumes, intake predictions in this study were not as accurate as previous predictions from the same data material using chemical analysis of silage samples (Krizsan and Randby, 2007; Krizsan et al., 2007). This is most likely because gas production variables are strongly correlated to the VFA concentration in silage, and therefore provide little additional information for intake predictions.

Often, model performance including gas production derived data has been ranked from the explained variation in forage intake rather than from accuracy measures of the prediction performance. Blümmel et al. (1997) achieved the highest explained variation in DMI of cereal straws and legume hay fed to sheep or steers from early gas volume measurements, in vitro degradability, and the calculated partitioning factor ( $\mathrm{mg}$ substrate degraded $\mathrm{ml}^{-1}$ of gas produced) at either 36 or $48 \mathrm{~h}$. Gas volumes during early fermentation represented the soluble feed fraction, degradabilities would be most influenced by the slowly fermentable feed fraction, and the partitioning factor partition substrate utilization between VFA production and yield of microbial biomass. We did not determine the partitioning factor in this study, which could have been valid to distinguish silage fermentation qualities with regard to energy available for rumen microbes during early hours of in vitro fermentation. The large increase in explained variation of forage DMI from including the partitioning factor (Blümmel et al., 1997) would be consistent with observations of higher intake of restrictively than extensively fermented silages (Jaakkola et al., 2006b; Krizsan and Randby, 2007). However, to be truly valid in relation to intake the partitioning factor should be measured close to peak microbial yield and before substantial microbial lysis have occured, which can be difficult to address to one time point representative for many feeds. Despite high explained variation in feed intake by gas production variables, relative errors of the predictions by Blümmel and Ørskov (1993) and Rodrigues et al. (2002) of 8.2 and $13.0 \%$, respectively, do not support that the method would 
be better than existing predictions primarily based on chemical analysis of feed parameters. Despite that only one trait (fermentation quality) was manipulated in this study, the smallest relative error when the prediction was based only on gas production derived data was $6.7 \%$. Huhtanen et al. (2007) modelled potential silage intake from chemical analysis of feed parameters and proportions of different forages included in the diet with a reported relative error of $3.1 \%$ within a study. That material comprised 486 dietary treatment means from dairy cow studies conducted at several locations and with intake ranging from 5.3 to $17.4 \mathrm{~kg}$ $\mathrm{DM} \mathrm{d}^{-1}$; intake predictions from gas production data have been narrower in range and mostly from forages produced from the same place.

\section{CONCLUSIONS}

The gas volume measurements in an early phase of the incubation as well as the simple discrete lag and cumulative gas volumes measured at 48 and $72 \mathrm{~h}$ were the best descriptors of the variation in dry matter intake (DMI) of silages differing in fermentation quality. The discrete lag time in the exponential model was the most important intake related variable in this interpretation; showing that depletion of the initial gas production was consistent with a lower intake of grass silages displaying poor fermentation quality. However, the prediction error of silage DMI was greater than reported earlier for models based on fermentation quality parameters. Not either did the large number of variables included in the partial least squares regression generate a substantially lower error than when a single gas production time point was used in a simple regression model of intake. It is concluded that in vitro gas production data is not likely to improve silage DMI predictions compared with the current models based on chemical analyses of the silage when only silage fermentation quality was manipulated, probably because the gas production variables are strongly correlated with silage variables typical for secondary fermentation.

\section{REFERENCES}

Abrams S.M., Harpster H.W., Wangsness P.J., Shenk J.S., Keck E., Rosenberger J.L., 1987. Use of a standard forage to reduce effects of animal variation on estimates of mean voluntary intake. J. Dairy Sci. 70, 1235-1240

Allen M.S., Mertens D.R., 1988. Evaluating constraints of fiber digestion by rumen microbes. J. Nutr. 118, 261-270

Beuvink J.M.W., Spoelstra S.F., 1994. In vitro gas production kinetics of grass silages treated with different cell wall-degrading enzymes. Grass Forage Sci. 49, 277-283 
Blümmel M., Bullerdieck P., 1997. The need to complement in vitro gas production measurements with residue determinations from in sacco degradabilities to improve the prediction of voluntary intake of hays. Anim. Sci. 64, 71-75

Blümmel M., Cone J.W., Van Gelder A.H., Nshalai I., Umunna N.N., Makkar H.P.S., Becker K., 2005. Prediction of forage intake using in vitro gas production methods: Comparison of multiphase fermentation kinetics measured in an automated gas test, and combined gas volume and substrate degradability measurements in a manual syringe system. Anim. Feed Sci. Tech. $123-124,517-526$

Blümmel M., Makkar H.P.S., Chisanga G., Mtimuni J., Becker K., 1997. The prediction of dry matter intake of temperate and tropical roughages from in vitro digestibility/gas production data, and the dry matter intak and in vitro digestibility of African roughages in relation to ruminant live weight gain. Anim. Feed Sci. Tech. 69, $131-141$

Blümmel M., Ørskov E.R., 1993. Comparison of in vitro gas production and nylon bag degradability of roughages in predicting feed intake in cattle. Anim. Feed Sci. Tech. 40, 109-119

Chai W.H., Udén P., 1998. An alternative oven method combined with different detergent strengths in the analysis of neutral detergent fibre. Anim. Feed Sci. Tech. 74, 281-288

Cone J.W., Van Gelder A.H., 1999. Influence of protein fermentation on gas production profiles. Anim. Feed Sci. Tech. 79, 251-264

Cone J.W., Van Gleder A.H., Driehuis F., 1997. Description of gas production profiles with a threephasic model. Anim. Feed Sci. Tech. 66, 31-45

Cone J.W., Van Gleder A.H., Visscher G.J.W, Oudshoorn L., 1996. Influence of rumen fluid and substrate concentration on fermentation kinetics measured with a fully automated time related gas production apparatus. Anim. Feed Sci. Tech. 61, 113-128

Dhanoa M.S., 1988. On the analysis of dacron bag data for low degradability feeds. Grass Forage Sci. 43, 441-444

France J., Dijkstra J., Dhanoa M.S., Lopez S., Bannink A., 2000. Estimating the extent of degradation of ruminant feeds from a description of their gas production profiles observed in vitro: derivation of models and other mathematical considerations. Brit. J. Nutr. 83, 143-150

Groot J.C.J., Cone J.W., Williams B.A., Debersaques F.M.A., Lantinga E.A., 1996. Multiphasic analysis of gas production kinetics for in vitro fermentation of ruminant feeds. Anim. Feed Sci. Tech. 64, 77-89

Hetta M., Cone J.W., Bernes G., Gustavsson A.-M., Martinsson K., 2007. Voluntary intake of silages in dairy cows depending on chemical composition and in vitro gas production characteristics. Livest. Sci. 106, 47-56

Hetta M., Cone J.W., Gustavsson A.-M., Martinsson K., 2003. The effect of additives in silages of pure timothy and timothy mixed with red clover on chemical composition and in vitro rumen fermentation characteristics. Grass Forage Sci. 58, 249-257

Huhtanen P., Ahvenjärvi S., Weisbjerg M.R., Nørgaard P., 2006a. Digestion and passage of fiber in ruminants. In: K. Sejrsen, T. Hvelpund, M.O. Nielsen (Editors). Ruminant Physiology. Wageningen Acad. Publ., Wageningen (The Netherlands), pp. 87-135

Huhtanen P., Khalili H., Nousiainen J.I., Rinne M., Jaakkola S., Heikkila T., Nousiainen J., 2002. Prediction of the relative intake potential of grass silage by dairy cows. Livest. Prod. Sci. 73, 111-130

Huhtanen P., Nousiainen J., Rinne M., 2006b. Recent developments in forage evaluation with special reference to practical applications. Agr. Food Sci. 15, 293-323

Huhtanen P., Nousiainen J.I., Rinne M., Kytölä K., Khalili H., 2008a. Utilization and partition of dietary nitrogen in dairy cows fed grass silage-based diets. J. Dairy Sci. 91, 3589-3599

Huhtanen P., Rinne M., Nousiainen J., 2007. Evaluation of the factors affecting silage intake of dairy cows: A revision of the relative silage dry-matter intake index. Animal 1, 758-770 
Huhtanen P., Seppälä A., Ahvenjärvi S., Rinne M., 2008b. Prediction of in vivo neutral detergent fiber digestibility and digestion rate of potentially digestible neutral detergent fiber: Comparison of models. J. Anim. Sci. 86, 2657-2669

Huhtanen P., Seppälä A., Ots M., Ahvenjärvi S., Rinne M., 2008c. In vitro gas production profiles to estimate extent and effective first-order rate of neutral detergent fiber digestion in the rumen. J. Anim. Sci. 86, 651-659

Huida L., Vaatainen H., Lampila M., 1986. Comparison of dry-matter contents in grass silages as determined by oven drying and gas-chromatographic water analysis. Ann. Agr. Fenniae 3, $215-$ 230

Jaakkola S., Kaunisto V., Huhtanen P., 2006a. Volatile fatty acid proportions and microbial protein synthesis in the rumen of cattle receiving grass silage ensiled with different rates of formic acid. Grass Forage Sci. 61, 282-292

Jaakkola S., Rinne M., Heikkilä T., Toivonen V., Huhtanen P., 2006b. Effects of restriction of silage fermentation with formic acid and milk production. Agr. Food Sci. 15, 200-218

Krizsan S.J., Randby Å.T., 2007. The effect of fermentation quality on the voluntary intake of grass silage by growing cattle fed silage as sole feed. J. Anim. Sci. 85, 984-996

Krizsan S.J., Westad F., Ådnøy T., Odden E., Aakre S.E., Randby Å.T., 2007. Effect of volatile compounds in grass silage on voluntary intake by cattle. Animal 1, 283-292

Martens H., Martens M., 2000. Modified jack-knife estimation of parameter uncertainty in bilinear modelling by partial least squares regression (PLSR). Food Qual. Preference 11, 5-16

Martens H., Martens M. (Editors), 2001. Multivariate Analysis of Quality: an Introduction. John Wiley, Chichester

McDonald P., Henderson A.R., Heron S.J.E., 1991. The Biochemistry of Silage. Chalcombe Publications, Marlow (UK)

Menke K.H., Steingass H., 1988. Estimation of the energetic feed value obtained from chemical analysis and in vitro gas production using rumen fluid. Anim. Res. Dev. 28, 7-25

Mertens D.R., 1993. Rate and extent of digestion. In: J.M. Forbes, J. France (Editors). Quantitative Aspects of Ruminant Digestion and Metabolism. CAB International, Wallingford (UK), pp. $13-50$

Mertens D.R., 1994. Regulation of forage intake. In: G.C. Fahey (Editor). Forage Quality, Evaluation and Utilization. ASA, CSSA, and SSSA, Madison, WI, pp. 450-493

Oldham J.D., 1984. Protein-energy interrelationships in dairy cows. J. Dairy Sci. 67, 1090-1114

Ørskov E.R., Reid G.W., Kay M., 1988. Prediction of intake of cattle from degradation characteristics of roughages. Anim. Prod. 46, 29-34

Pell A.N., Schofield P., 1993. Computerized monitoring of gas production to measure forage digestion in vitro. J. Dairy Sci. 76, 1063-1073

Rodrigues M.A.M., Fonseca A.J.M., Sequeira C.A., Dias-da-Silva A.A., 2002. Digestion kinetic parameters from an in vitro gas production method as predictors of voluntary intake of forage by mature ewes. Anim. Feed Sci. Tech. 95, 133-142

Schofield P., Pell A.N., 1995. Measurement and kinetic analysis of the neutral detergent-soluble carbohydrate fraction of legumes and grasses. J. Anim. Sci. 73, 3455-3463

Schofield P., Pitt R.E., Pell A.N., 1994. Kinetics of fiber digestion from in vitro gas production. J. Anim. Sci. 72, 2980-2991

Steen R.W.J., Gordon F.J., Dawson L.E.R., Park R.S., Mayne C.S., Agnew R.E., Kilpatrick D.J., Porter M.G., 1998. Factors affecting the intake of grass silage by cattle and prediction of silage intake. Anim. Sci. 66, 115-127 